\title{
MECHANICAL PROPERTIES OF VARIOUS CONCRETE AFTER HIGH TEMPERATURE EXPOSURE
}

\author{
Sung-Hoon Kang ${ }^{1}$, Min-Soo Kim² \& Sung-Gul Hong ${ }^{3}$
}

Abstract- Mechanical property of various types of concrete after high temperature exposure is investigated. Considering compressive strength requirement for a vertical element in high rise building, concrete specimens with various design strengths of 35, 80, 100, and $150 \mathrm{MPa}$ were tested. Particularly, the influence of incorporated steel fiber on fire resistance is of int erest in this study. Experimental results show that the fire resistance depends on the design strength and steel fiber content. Normal strength concrete (NSC) of a design strength of 35 MPa or high performance concrete (HPC) of 80-100 MPa does not spall when exposed to $100-400{ }^{\circ} \mathrm{C}$ of temperature. However, an explosive spalling occurs at $300{ }^{\circ} \mathrm{C}$ when the HPCs contain 1 vol. $\%$ of steel fiber. Ultra-high performance concrete (UHPC) of a design strength of $150 \mathrm{MPa}$ and 1.5 vol.\% of steel fiber also shows dramatic spalling at $300{ }^{\circ} \mathrm{C}$. The experimental results found in this study can contribute to a better understanding of the behaviors of HPC and UHPC under fire and the role of steel fiber on the fire resistance.

Keywords - Ultra-High Performance Concrete, High Performance Concrete; Fire Resistance; Spalling; High Temperature

\section{INTRODUCTION}

It is generally known that the mechanical performance decreases when a concrete is exposed to high temperatures. In particular, the reduction of the performance becomes more pronounced with a higher strength, and even a brittle failure such as explosion may occur. This type of failure, known as explosive spalling, is due to the sudden splitting of concrete into numerous pieces at high temperature [1,2].

When a concrete is exposed to high temperature, various types of internal water (free water, capillary water, and adsorbed water) are desorbed or evaporated and converted into vapor or gas [3]. This gas, whose volume has been significantly expanded, increases the internal water vapor pressure and eventually cracks the concrete [4]. Compared with normal strength concrete (NSC), high strength or high performance concrete (HPC) makes it difficult for internal water vapor to escape out. This is due to its dense internal structure and low permeability, resulting in much greater internal pressure [5]. Therefore, the explosive spalling that is a totally different phenomenon compared to that NSC experiences [3]. Phan and Carino reported that this type of spalling occurs between $200-325^{\circ} \mathrm{C}[6]$.

The structural elements of high-rise buildings or skyscrapers are typically made of various types of concrete to effectively resist self-weight and wind load. In particular, vertical elements such as columns can have different compressive strengths in the range of 30-150 MPa depending on their vertical position. In other words, as a vertical load applied to the elements increases, the design compressive strength should be increased unless the cross-section area is increased. Moreover, in the case of high or ultra-high strength concrete, whose design strength is $80 \mathrm{MPa}$ or higher, steel fiber is frequently included to alleviate its brittle failure characteristic. Therefore, in order to accurately evaluate the structural safety of fire-exposed high-rise buildings, the mechanical performance of concrete with various strengths at high temperatures should be firstly investigated.

In this study, the mechanical properties of concrete after high temperature exposure were investigated. The compressive strength and spalling characteristics of concrete of various design strengths $(35,80,100$ and $150 \mathrm{MPa})$ were evaluated by experiments. In addition, the effect of incorporated steel fiber on the fire resistance was examined. The results of this study can contribute to assess structural safety or to develop guidelines of fire resistance for high-rise buildings.

\section{EXPERIMENTAL PROGRAM}

A. Preparation of Concrete Specimens

As shown in Table 1, six concrete samples were prepared. They are distinguished by four design strengths and the presence of steel fibers. NSC has a design strength of $35 \mathrm{MPa}$ and the HPC has two different design strengths of $80 \mathrm{MPa}$ and $100 \mathrm{MPa}$. HPC(SFRC) contains 1\% (by volume of concrete) of steel fibers in HPC while other conditions are the same with HPC. UHPC has a design strength of $150 \mathrm{MPa}$, which meets the requirement for this type of concrete [7,8]. All concretes in Table 1 are commercially available in Korea, and the specimens for the experiment were manufactured in precast concrete plants.

\footnotetext{
${ }^{1}$ Department of Architecture \& Architectural Engineering, Seoul National University, Seoul, Republic of Korea

${ }^{2}$ Department of Architecture \& Architectural Engineering, Seoul National University, Seoul, Republic of Korea

${ }^{3}$ Department of Architecture \& Architectural Engineering, Seoul National University, Seoul, Republic of Korea
} 
Table -1 Mix proportion and design strength of concrete used

\begin{tabular}{|c|c|c|c|c|c|c|c|c|c|}
\hline \multirow[b]{2}{*}{$\begin{array}{l}\text { Type of } \\
\text { concrete }\end{array}$} & \multirow{2}{*}{$\begin{array}{l}\text { Design } \\
\text { strengt } \\
\text { h } \\
(\mathrm{MPa})\end{array}$} & \multirow[b]{2}{*}{$\underset{1)}{\mathbf{W} / B}$} & \multicolumn{7}{|c|}{$\operatorname{Mass}\left(\mathbf{k g} / \mathbf{m}^{3}\right)$} \\
\hline & & & $\begin{array}{l}\text { Wate } \\
\text { r }\end{array}$ & $\begin{array}{l}\text { Pre-mix } \\
\text { powder }\end{array}$ & Sand & $\begin{array}{l}\text { Coarse } \\
\text { aggregate }\end{array}$ & Steel fiber & $\begin{array}{l}\text { Chemica } \\
\text { l } \\
\text { admixtu } \\
\text { re } \\
\end{array}$ & $\begin{array}{l}\text { Air } \\
\text { reducin } \\
\text { g agent }\end{array}$ \\
\hline NSC & 35 & 0.42 & 160 & 381 & 826 & 942 & 0 & 3 & \multirow{5}{*}{ NA } \\
\hline \multirow{2}{*}{ HPC } & 80 & 0.188 & 150 & 800 & 578 & 882 & 0 & 10 & \\
\hline & 100 & 0.149 & 140 & 940 & 484 & 876 & 0 & 12 & \\
\hline \multirow{2}{*}{$\begin{array}{l}\text { HPC(SFR } \\
\text { C) }\end{array}$} & 80 & 0.188 & 150 & 800 & 578 & 882 & 78 & 10 & \\
\hline & 100 & 0.149 & 140 & 940 & 484 & 876 & 78 & 12 & \\
\hline UHPC & 150 & 0.2 & 197 & 1270 & 867 & NA & 117 & 18 & 0.5 \\
\hline
\end{tabular}

1) Water to binder ratio, binder is composed of ordinary Portland cement (OPC), silica fume (SF), fly-ash (FA), and ground granulated blast-furnace slag (GGBFS)

2) $\mathrm{OPC}+\mathrm{FA}+\mathrm{GGBFS}$ for NSC, $\mathrm{OPC}+\mathrm{SF}+\mathrm{GGBFS}$ for $\mathrm{HPC}, \mathrm{OPC}+\mathrm{SF}+$ quartz powder for UHPC

3) $\Phi 0.5 \times 30 \mathrm{~mm}$ for HPC ( 1 vol. $\%), \Phi 0.2 \times 16 \mathrm{~mm}(0.5$ vol.\% $)+\Phi 0.2 \times 20 \mathrm{~mm}(1 \mathrm{vol} . \%)$ for UHPC (1.5 vol.\%)

\section{B. Test Program -}

Cylinder specimens based on the mix proportions in Table 1 were prepared to investigate compressive strength of concrete after high temperature exposure. In the case of UHPC, typical heat treatment process (stream curing at $90{ }^{\circ} \mathrm{C}$ for 48 hours) was applied between 2-4 days of curing ages, to accelerate strength development [7-9]. Except for this UHPC, all specimens were cured at room temperature $\left(23{ }^{\circ} \mathrm{C}\right.$, RH $\left.60 \%\right)$. At 28 days, the strength test was performed according to the ASTM standards using a universal testing machine [10]. Based on this test result, it was confirmed that all the concrete satisfies the planned design strength.

The specimens cured for over 28 days were exposed to high temperature using an electric furnace. The heating program shown in Figure 1 was planned according to previous study [11]. Above all, to protect the equipment from explosive spalling of concrete, a $2.5 \mathrm{~mm}$ thick stainless steel frame was installed inside the equipment. After the specimens were placed in the frame, the inside of the equipment was heated to the target temperature of $100{ }^{\circ} \mathrm{C}, 200{ }^{\circ} \mathrm{C}, 300{ }^{\circ} \mathrm{C}$, or $400{ }^{\circ} \mathrm{C}$ at a rate of $2{ }^{\circ} \mathrm{C} / \mathrm{min}$. Once the target temperature was reached, it was maintained for one hour and then dropped back to the room temperature (23 ${ }^{\circ} \mathrm{C}$ ). As soon as the inside temperature reached $23^{\circ} \mathrm{C}$, the specimens were removed from the equipment and the strength test was performed.

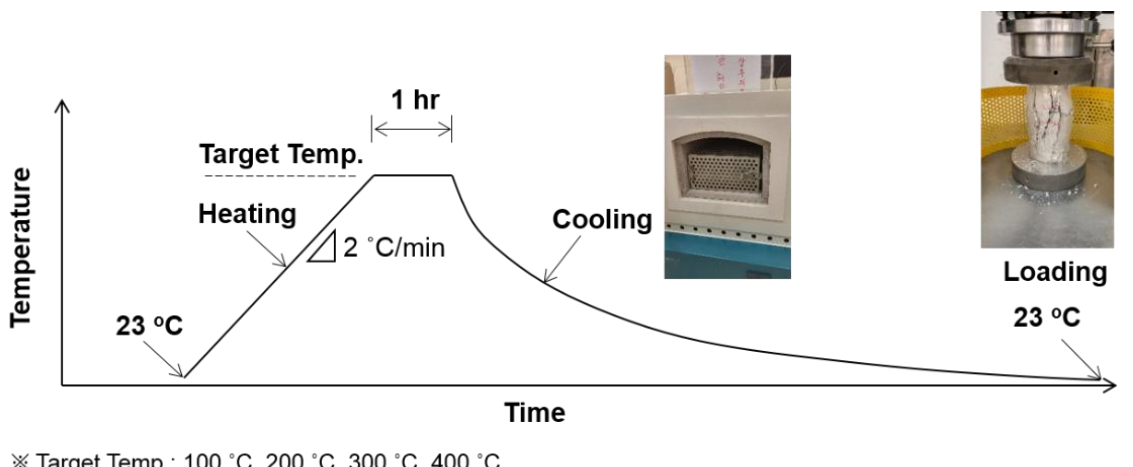

Figure 1. Heating program

\section{RESULTS}

3.1 Concrete Spalling at High Temperature -

Figure 2 shows the state of concrete after high temperature exposure. NSC did not show any visible damage up to $400{ }^{\circ} \mathrm{C}$. HPC of 80-100 MPa also maintained its original shape up to $400{ }^{\circ} \mathrm{C}$. However, they showed completely different results when containing steel fibers. When exposed to $200-400{ }^{\circ} \mathrm{C}$, explosive spalling occurred in HPC; this phenomenon was more prominent in concrete with higher strength (compare $80 \mathrm{MPa}$ and $100 \mathrm{MPa}$ of $\mathrm{HPC}(\mathrm{SFPC})$ ). UHPC which contains steel fibers also experienced the explosive spalling accompanied by a tremendous impact at temperatures above $200{ }^{\circ} \mathrm{C}$. As a result, the stainless steel frame was bent, as shown in Figure 3 (b). 


\subsection{Change in Compressive Strength after High Temperature Exposure -}

The changes in strength of concrete after high temperature exposure are presented in Figure 3. First of all, it is confirmed in all samples that the compressive strength at $23^{\circ} \mathrm{C}$ is higher than the design strength. However, in the case of NSC, the compressive strength decreased steadily with increasing temperature. After exposed to the temperature of $300-400{ }^{\circ} \mathrm{C}$, the measured strength was lower than the design strength, and the strength decreased by $42 \%$ at $400{ }^{\circ} \mathrm{C}$ compared to that at $23{ }^{\circ} \mathrm{C}$. The strength of HPC did not decrease up to $300{ }^{\circ} \mathrm{C}$ but showed a tendency to decrease above $300{ }^{\circ} \mathrm{C}$. As a result, the concrete exposed to 400 ${ }^{\circ} \mathrm{C}$ did not satisfy the design strength. Furthermore, the strength reduction ratio at $400{ }^{\circ} \mathrm{C}$ was up to $27 \%$, which is lower than NSC.

The strength of concrete with steel fibers, (i.e., HPC(SFRC) and UHPC) also did not decrease up to $200{ }^{\circ} \mathrm{C}$. Interestingly, at this temperature range $\left(23-200{ }^{\circ} \mathrm{C}\right)$, the strength of UHPC increased significantly with temperature rise. In other words, the compressive strength, which was $165 \mathrm{MPa}$ at room temperature, increased to $228 \mathrm{MPa}$ after exposure to the high temperature of $200{ }^{\circ} \mathrm{C}$. This can be explained by the secondary heat treatment effect of UHPC, which is possible at $150{ }^{\circ} \mathrm{C}$ or higher [12-14]. However, it was impossible to measure the strength of HPC(SFRC) and UHPC after exposed to $300-400{ }^{\circ} \mathrm{C}$, because of the explosive spalling. In this case, their load-carrying capacities can be considered to be completely lost.

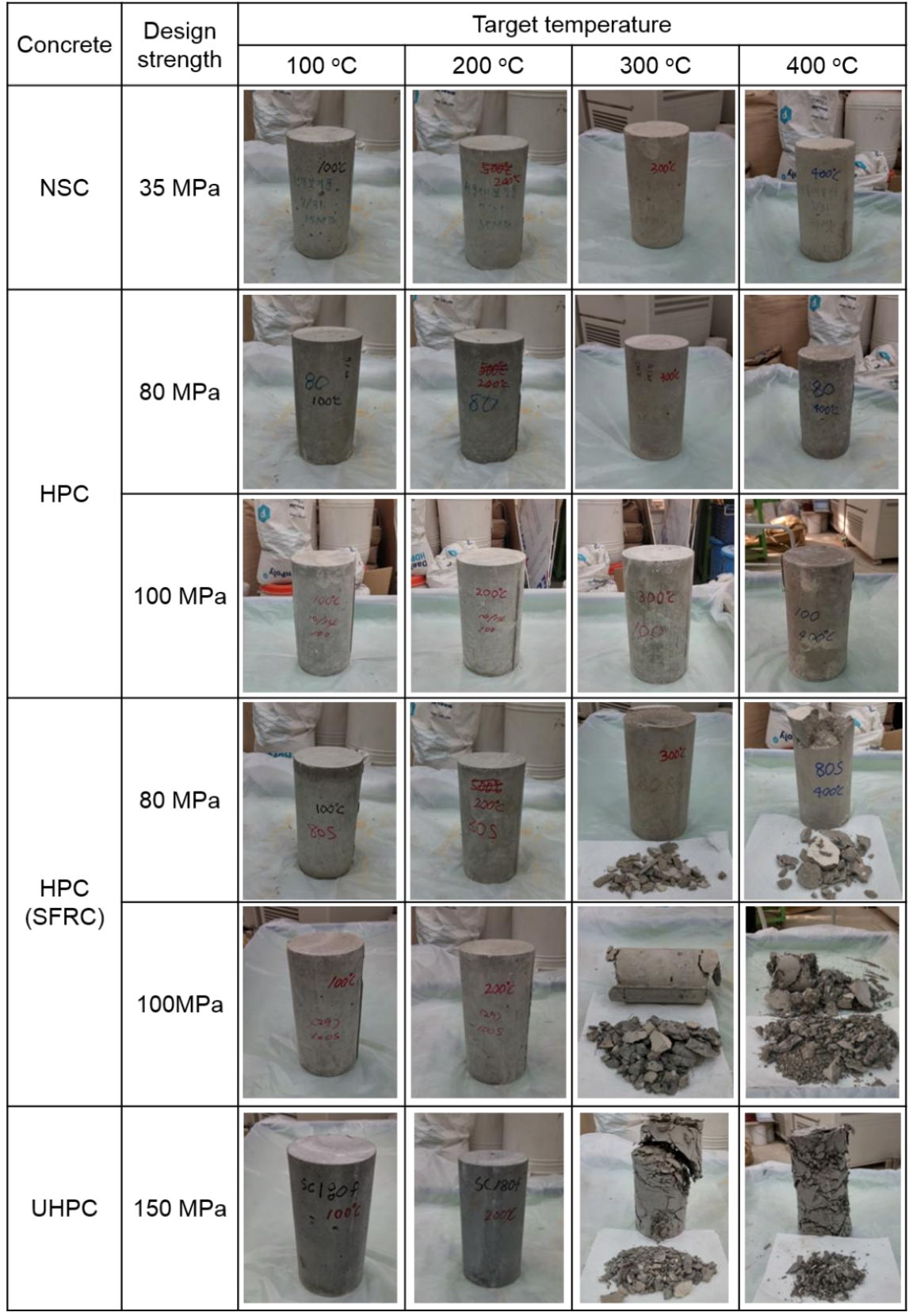

Figure 2. Concrete specimens after high temperature exposure 

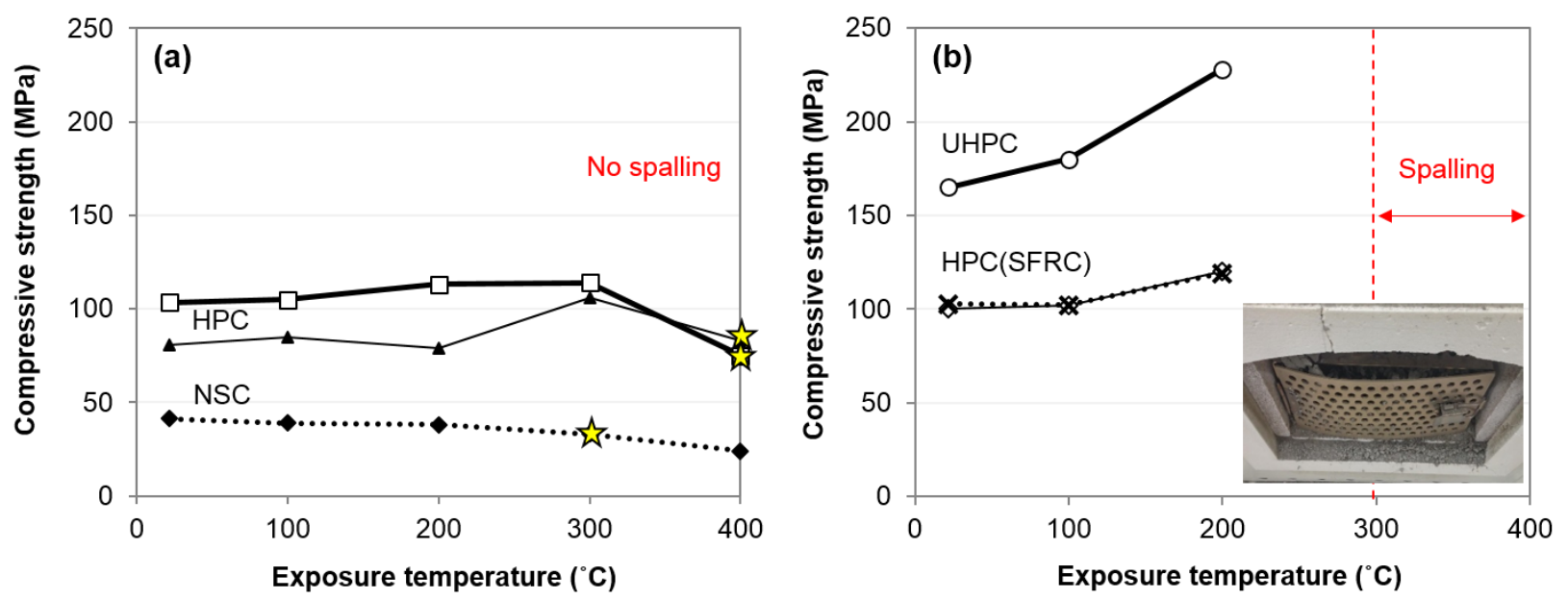

Figure 1.

Compressive strength of concrete exposed to high temperature: (a) NSC and HPC without steel fiber (b) HPC and UHPC with steel fiber. The stars on the figure indicate the temperature when the measured strength is lower than the designed strength.

\section{DISCUSSION}

4.1 Behavior of Concrete with Various Strengths and Mix Proportions at High Temperature -

Typically, compressive strength of concrete increases when the microstructure becomes denser. The typical method for improving the strength or microstructure is to reduce the water to cement (or binder) ratio. In addition to this, HPC or UHPC features to include silica fume in their mix proportions (see Table 1). This ultra-fine particle not only acts as a physical filler that fills sub-micro sized voids of concrete, but also contributes to making the concrete stronger by the pozzolanic reaction with water and portlandite which is formed by primary cement hydration $[15,16]$. The pozzolanic reaction progresses slowly over time, but it is accelerated with increasing curing temperature and eventually contributes to an additional increase in strength. Therefore, the reason for that the compressive strength of concrete with SF further increases when it is exposed to a high temperature can be explained (Figure 3). In addition, the strength of UHPC increased significantly between $100{ }^{\circ} \mathrm{C}$ and $200{ }^{\circ} \mathrm{C}$. This is because, in addition to the contribution of SF, crystalline quartz powder contained only in UHPC is activated at temperatures above $150{ }^{\circ} \mathrm{C}$; it may participate in additional hydration reactions, and thus the matrix becomes denser [13, 17]. However, despite this increase in strength, the concrete failed to withstand generated internal vapor pressure and eventually exploded at a temperature of $200-300{ }^{\circ} \mathrm{C}$. When cement pastes are exposed to a temperature of about $300{ }^{\circ} \mathrm{C}$, parts of the interlayer C-S-H water and chemically bound water are desorbed, which can contribute to the increase of vapor pressure [3].

\subsection{Effect of Steel Fiber on Fire Resistance of Concrete -}

In our study, it was confirmed that HPCs were explosive at lower temperatures when they contained steel fibers. In other words, the thermal expansion was accelerated when steel fiber was included in the concrete. Both the coefficient of thermal expansion and the thermal conductivity of steel are higher than those of concrete. Therefore, even if exposed to the same temperature, the concrete containing the steel fiber in its entire volume can not only transfer heat to the inside faster, but also expand itself (i.e., steel fiber) more significantly. As a result, the higher the ratio of steel fiber in concrete, the lower the compressive strength after high temperature exposure [18]. This can be confirmed by comparing HPC and UHPC in this study. Compared with HPC, UHPC contains 50\% more steel fibers, and their length and diameter are shorter, so it is evenly distributed throughout the volume. In summary, UHPC is more vulnerable to explosion compared to other types of concrete such as NSC or HPC, and as mentioned, spalling occurs with a very large impact between $200{ }^{\circ} \mathrm{C}$ and $300{ }^{\circ} \mathrm{C}$. Therefore, if UHPC is used as a structural element of a building, a solution for ensuring fire resistance shall be considered in advance.

\section{CONCLUSION}

The compressive strength of concrete with various strength after high temperature exposure was investigated experimentally. Based on the results, the following conclusions can be drawn.

1) NSC and HPC did not show spalling when exposed to high temperatures of $100-400{ }^{\circ} \mathrm{C}$. However, after exposure to $400{ }^{\circ} \mathrm{C}$, their compressive strengths were decreased by $42 \%$ and $27 \%$, respectively, compared to the strength at room temperature (23 $\left.{ }^{\circ} \mathrm{C}\right)$.

2) HPC(SFRC) and UHPC which include steel fiber showed explosive spalling after exposed to the temperature of $200-300{ }^{\circ} \mathrm{C}$. Thus, their load-carrying capacities are completely lost at this temperature range. However, the compressive strength tended to increase with increasing temperature at the temperature below $200{ }^{\circ} \mathrm{C}$. In particular, the strength of UHPC increased by $38 \%$ after exposed to $200{ }^{\circ} \mathrm{C}$, compared to the strength at $23^{\circ} \mathrm{C}$. 
3) The steel fiber had a negative effect on the fire resistance of concrete. In the UHPC in which the volume ratio and number of steel fibers are higher than the HPC, spalling occurred with much greater impact than that seen in HPC. Therefore, in order to utilize UHPC for building structure, the fire resistance should be more importantly considered.

\section{ACKNOWLEDGMENT}

This research was supported by a grant (13SCIPA02) from Smart Civil Infrastructure Research Program funded by Ministry of Land, Infrastructure and Transport (MOLIT) of Korea government and Korea Agency for Infrastructure Technology Advancement (KAITA). The Institute of Engineering Research in Seoul National University provided research facilities for this work.

\section{REFERENCES}

[1] T.P. Long, J.C. Nicholas, Effects of Test Conditions and Mixture Proportions on Behavior of High-Strength Concrete Exposed to High Temperatures, Materials Journal, 99.

[2] P. Kalifa, F.-D. Menneteau, D. Quenard, Spalling and pore pressure in HPC at high temperatures, Cem. Concr. Res., 30 (2000) $1915-1927$.

[3] P.K. Mehta, P.J. Monteiro, Concrete-microstructure, properties and materials, McGeaw-Hill, New York, USA, 2006.

[4] L.T. Phan, International Workshop on Fire Performance of High-Strength Concrete, NIST, Gaithersburg, MD, February 13-14, 1997, Proceedings, Special Publication (NIST SP)-919, (1997).

[5] L.T. Phan, Pore pressure and explosive spalling in concrete, Mater. Struct., 41 (2008) 1623-1632.

[6] L.T. Phan, N.J. Carino, Review of mechanical properties of HSC at elevated temperature, Journal of Materials in Civil Engineering, 10 (1998) 58-65.

[7] Association Française de Génie Civil (AFGC), Ultra high performance fibre-reinforced concrete-Recommendations (Revised edition), Paris, France, 2013.

[8] Japan Society of Civil Engineers (JSCE), Recommendations for design and construction of ultra high-strength fiber-reinforced concrete structures-Draft (in Japanese), Tokyo, Japan, 2004.

[9] Korea Concrete Institute (KCI), Design recommendations for K-UHPC (in Korean), Seoul, Korea, 2012.

[10] ASTM C39, Standard test method for compressive strength of cylindrical concrete specimens, ASTM international, West Conshohocken, Pennsylvania, USA, 2016, pp. 7.

[11] M. Behloul, G. Chanvillard, P. Casanova, G. Orange, F.F.F. France, Fire resistance of Ductal® ultra high performance concrete, 1st fib Congress, 2002, pp. 421-430.

[12] P. Richard, M. Cheyrezy, Composition of reactive powder concretes, Cem. Concr. Res., 25 (1995) $1501-1511$.

[13] H. Zanni, M. Cheyrezy, V. Maret, S. Philippot, P. Nieto, Investigation of hydration and pozzolanic reaction in reactive powder concrete (RPC) using 29 Si NMR, Cem. Concr. Res., 26 (1996) 93-100.

[14] M. Reda, N. Shrive, J. Gillott, Microstructural investigation of innovative UHPC, Cem. Concr. Res., 29 (1999) 323 -329.

[15] Y.-H. Kwon, S.-H. Kang, S.-G. Hong, J. Moon, Acceleration of intended pozzolanic reaction under initial thermal treatment for developing cementless fly ash based mortar, Materials, 10 (2017) 225.

[16] Y.-H. Kwon, S.-H. Kang, S.-G. Hong, J. Moon, Intensified pozzolanic reaction on kaolinite clay-based mortar, Appl. Sci., 7 (2017) 522.

[17] I. Schachinger, H. Hilbig, T. Stengel, Effect of curing temperature at an early age on the long-term strength development of UHPC, 2nd International Symposium on Ultra High Performance Concrete, Kassel University, Kassel, Gemany, 2008, pp. $205-212$.

[18] W. Zheng, B. Luo, Y. Wang, Stress-strain relationship of steel-fibre reinforced reactive powder concrete at elevated temperatures, Mater. Struct., 48 (2015) 2299-2314 